\title{
Alelopatia de extratos aquosos de Duranta repens sobre a germinação e o crescimento inicial de Lactuca sativa e Lycopersicum esculentum
}

\author{
Celia Maria Tur \\ Junior Borella* \\ Lindamir Hernandez Pastorini \\ Universidade Regional Integrada do Alto Uruguai e das Missões \\ Departamento de Ciências Biológicas, CEP 98400-000, Frederico Westphalen - RS, Brasil \\ *Autor para correspondência \\ borellaj@gmail.com
}

Submetido em 10/08/2009

Aceito para publicação em 02/03/2010

\section{Resumo}

Alelopatia pode ser definida como efeito maléfico ou benéfico que uma planta exerce sobre a outra por meio de compostos químicos liberados no meio ambiente. No presente trabalho, foram investigados os efeitos alelopáticos de extratos aquosos de folhas frescas, secas e frutos de pingo-de-ouro na germinação e no crescimento inicial da alface e tomate. Extratos aquosos foram preparados nas concentrações de 1\%, 2\% e 4\% (m/v) e caracterizados quanto ao $\mathrm{pH}$ e potencial osmótico. Também foram realizadas análises fitoquímicas das folhas e frutos. Para a germinação foram avaliados a porcentagem de germinação (PG), a velocidade de germinação (VG) e o índice de velocidade de germinação (IVG). O crescimento inicial foi avaliado pelo comprimento (radicular e da parte aérea) e pela massa (fresca, seca e conteúdo de água). Extratos de folhas frescas e secas alteraram a PG do tomate e a VG e IVG da alface e tomate. Todos os extratos alteram o comprimento radicular da alface e do tomate, o comprimento da parte aérea e a massa (seca e fresca) da alface. A análise fitoquímica revelou a presença de saponinas e flavonóides. A ação dos extratos foi desassociada de qualquer efeito do potencial osmótico e do $\mathrm{pH}$, indicando, portanto, atividade alelopática.

Unitermos: crescimento inicial, efeito alelopático, germinação, pingo-de-ouro

\section{Abstract}

Allelopathic effects of aqueous extracts of Duranta repens on the germination and early growth of Lactuca sativa and Lycopersicum esculentum. Allelopathy can be defined as any stimulatory or inhibitory effect by one plant on another through production of chemical compounds released into the environment. In this work, the effects of aqueous extracts of Duranta repens fresh, dried leaves and fruit on the germination and early growth of lettuce and tomato were investigated. Aqueous extracts at concentrations of $1 \%, 2 \%$ and $4 \%(\mathrm{w} / \mathrm{v})$ were prepared and characterized as to $\mathrm{pH}$ and osmotic potential. Phytochemical analysis of leaves and fruits was also carried out. Germination parameters consisted of the percentage of germination (PG), speed of germination (VG) and speed of germination index (IVG). Initial growth was evaluated through length (root and shoot) and mass (fresh, dried and water content). Extracts of fresh and dry leaves altered the tomato PG and 
lettuce and tomato VG and IVG. All extracts affected the root length of the lettuce and tomato, as well as the length of the shoots and mass (dry and fresh) of the lettuce. The phytochemical analysis revealed the presence of saponins and flavonoids. The action of the extracts was disassociated from any effect of osmotic potential and $\mathrm{pH}$, indicating allelopathic activity.

Key words: allelopathic effect, Duranta repens, early growth, germination

\section{Introdução}

O termo alelopatia foi cunhado por Molisch em 1937 e tem sido empregado para caracterizar interações bioquímicas entre todos os tipos de plantas, inclusive microorganismos. Tais interações ocorrem devido à ação de substâncias químicas (aleloquímicos) produzidos via metabolismo secundário das plantas e liberadas no meio ambiente (Rice, 1984). Segundo Rizvi et al. (1992), é quase impossível enumerar cada um dos compostos hoje considerados alelopáticos, devido à grande diversidade e quantidade. Entre os compostos com atividades alelopáticas, destacam-se: taninos, glicosídeos cianogênicos, alcalóides, sesquiterpenos, flavonóides, ácidos fenólicos e outros (King e Ambika, 2002).

As substâncias químicas são produzidas em diferentes órgãos das plantas, como raízes, folhas, flores e frutos (Delachiave et al., 1999) e sua concentração nos tecidos dependem de diversos fatores, como temperatura, pluviosidade, luminosidade, entre outros. A produção de aleloquímicos pelas plantas tem fundamental importância no que diz respeito à auto defesa (Macías et al., 2007). Esse mecanismo de defesa das plantas foi adquirido ao longo de um processo de evolução e representa um importante mecanismo ecológico que influencia direta e indiretamente as plantas adjacentes (Chou, 1999; 2006), que é propiciada pela liberação dos aleloquímicos por diferentes formas (volatilização, exsudação radicular, lixiviação e decomposição de resíduos). No entanto, para que a ação seja eficaz a liberação deve ser contínua, de modo que os efeitos persistam até as culturas subsequentes (Rodrigues et al., 1999).

Efeitos fisiológicos ocasionados por interações alelopáticas, frequentemente observados, são inibição da porcentagem e velocidade da germinação e na redução do crescimento inicial, sendo estes respostas secundárias de efeitos primários que ocorrem no processo metabólico das plantas afetadas (Pedrol et al.,
2006). Entre os efeitos diretos observam-se interferências no crescimento e no metabolismo vegetal, englobando alterações em nível celular, fitormonal, fotossintético e respiratório, síntese protéica, metabolismo lipídico e ácidos orgânicos, inibição ou estimulação da atividade enzimática específica, efeitos sobre a relação hídrica e sobre a síntese de DNA ou RNA nas plantas alvo. Efeitos indiretos compreendem interferência na produtividade da agricultura, de agroecossistemas e na biodiversidade local, por causar alterações na sucessão vegetal, na estrutura e composição das comunidades vegetais e na dominância de certas espécies vegetais (Rizvi et al., 1992; Chou, 1999; 2006). Os efeitos observados são resultados de uma interação complexa entre fatores genéticos e ambientais (Rodrigues et al., 1999).

O desejo crescente de substituir os insumos químicos sintéticos nos agroecossistemas por materiais produzidos naturalmente motiva pesquisas aplicada à alelopatia, isto porque os benefícios da pesquisa alelopática podem ser utilizados para melhorar a sustentabilidade de nossos sistemas de produção e a conservação da vegetação natural ou seminatural, pois representam uma alternativa biológica com ação específica e menos prejudicial ao meio ambiente (Smith e Martin, 1994; Macías et al., 1998; Chou, 1999; 2006; Olofsdotter e Mallik, 2001).

Bioensaios laboratoriais envolvendo investigações alelopáticas são de grande importância, pois no laboratório podemos controlar muitos parâmetros que na natureza interagem simultânea e sequencialmente, além de mudarem constantemente (Inderjit e Dakshini, 1995). Pesquisas alelopáticas no Brasil são necessárias, pois pouco se conhece a respeito das potencialidades das plantas e o benefício que as mesmas podem proporcionar (Ferreira et al., 1992).

O pingo-de-ouro (Duranta repens L; "Aurea"), Verbenaceae, é uma planta exótica originária do México 
e amplamente difundida no Brasil. Consiste num arbusto lenhoso que pode atingir até $1,5 \mathrm{~m}$ de altura. Apresenta folhas inteiras amarelo-dourado, de disposição alterna ou aposta, principalmente nas folhas jovens, os frutos são alaranjados, drupáceos ou secos e esquizocarpos, ou ainda secos e alados pelo cálice. $\mathrm{O}$ pingo-de-ouro é muito utilizado em áreas de jardinagem e canteiros de vias urbanas, em bordaduras e renques a pleno sol, pode ser podado em variadas formas, moldando o espaço onde se encontra. Prefere climas quentes, úmidos e luminosidade, além de não apresentar exigências na adaptação e cultivo, possui rápido crescimento e é propagado principalmente por meio de estaquias, no período de outono e inverno (Lorenzi e Souza, 2001).

Foi observado que o pingo-de-ouro atinge um porte maior em relação a outras plantas, que estes podiam interferir no estabelecimento e desenvolvimento de plantas que crescem em sua proximidade, principalmente quando da poda, cujas folhas e frutos caem e cobrem o solo ao seu entorno. Além do mais, esta espécie tem como característica ser de rápido crescimento, ser pouco exigente ao tipo de solo para o plantio e não requer frequentes irrigações, não necessitando de nenhum ou pouco cuidado para o seu estabelecimento, o que pode ser considerado vantajoso comparado às demais espécies. Nesse contexto, o objetivo do trabalho foi verificar o possível efeito alelopático de diferentes concentrações de extratos aquosos de folhas frescas, secas e frutos de Duranta repens L. "Aurea", sobre a germinação e o crescimento inicial de aquênios de alface (Lactuca sativa L.) e tomate (Lycopersicum esculentum L.), por meio de bioensaios laboratoriais.

\section{Material e Métodos}

O material vegetal foi coletado em jardins e canteiros urbanos do município de Frederico Westphalen, no mês de novembro de 2007, levados para o laboratório de Fisiologia Vegetal da Universidade Regional Integrada do Alto Uruguai e das Missões (URI), Campus de Frederico Westphalen, onde se obteve os extratos.

Após a coleta, folhas frescas, folhas secas e frutos foram separados, pesados nas proporções de 1, 2 e $4 \mathrm{~g}$ e macerados com gral e pistilo e diluídos em 100mL de água destilada $(\mathrm{m} / \mathrm{v})$, obtendo-se assim os extratos nas concentrações 1, 2 e 4\%. Em seguida, estes extratos foram filtrados em papel-filtro, e acondicionados em vidros âmbar, tampados e mantidos no refrigerador. Folhas frescas foram coletadas e secas em temperatura ambiente de laboratório $\left( \pm 25^{\circ} \mathrm{C}\right)$, durante uma semana, protegida de luz e umidade, do qual se obteve os extratos de folhas secas. A fim de comparar os efeitos dos extratos utilizou-se água destilada como controle $(0 \%)$.

Para verificar os efeitos dos extratos, foram realizados testes de germinação em placas de Petri esterilizadas ( $9 \mathrm{~cm}$ de diâmetro), sendo cada placa forrada com duas folhas de papel Germitest ao fundo e umedecidas com $5 \mathrm{~mL}$ dos extratos obtidos ou água destilada. Após o primeiro dia de incubação das placas foram acrescentados mais $2 \mathrm{~mL}$ de extrato ou água nas placas. $\mathrm{O}$ delineamento experimental adotado foi totalmente casualizado com quatro tratamentos de quatro repetições de 25 aquênios de alface (Lactuca sativa L. cv. "Grand rapids") ou tomate (Lycopersicum esculentum L. cv. "Santa cruz kada"), obtidas em comércio local.

As placas de Petri identificadas pelas sementes e extratos permaneceram em germinador tipo B.O.D., a $25^{\circ} \mathrm{C}$ por 5 dias. A contagem da germinação foi realizada diariamente, tendo como critério para germinação a emergência da radícula ( $2 \mathrm{~mm}$ de protusão radicular) (Ferreira e Áquila, 2000). Para análise da germinação, foram avaliados a porcentagem de germinação (PG), a velocidade de germinação (VG) e o índice de velocidade de germinação, de acordo com Vieira e Carvalho (1994). Para análise de crescimento inicial foram efetuadas medidas da radícula e da parte aérea de 10 plântulas por extrato, com auxílio de régua milimetrada e a pesagem da massa fresca, utilizando balança analítica, posteriormente as plântulas foram acondicionadas em estufa e mantidas por $72 \mathrm{~h} \mathrm{a} 70^{\circ} \mathrm{C}$, para obtenção da massa seca. O conteúdo de água foi calculado de acordo com Marenco e Lopes (2005). A germinação e o crescimento inicial foram analisados a partir dos mesmos testes.

Os resultados obtidos foram submetidos à ANOVA e comparados pelo teste de Tukey a $5 \%$ de probabilidade, usando o programa BioEstat 5.0.

Foram realizados ainda testes físico-químicos, analisando o pH, através de pHmetro (Villela et al., 1991) 
e o potencial osmótico - PO, estimado pelo método de Chardakov, sendo posteriormente transformados em MPa (Salisbury e Ross, 1992) de todas as concentrações dos extratos de pingo-de-ouro. Análises fitoquímicas qualitativas dos extratos das folhas frescas e secas e dos frutos de pingo-de-ouro foram realizadas para identificar aleloquímicos presentes nesta planta. Foram realizadas análises de quatro grupos de metabólitos secundários: saponinas, taninos, flavonóides e alcalóides.

Para a realização dos testes de caracterização, foi seguida a metodologia de Costa (2001) e Falkenberg et al. (2002). A detecção dos compostos foi realizado por meio de reações específicas, cuja presença ou ausência do aleloquímico foi identificada pela formação de precipitado ou aparecimento de coloração específica nas reações: 1 - taninos (métodos: reação com cloreto férrico, reação com acetato neutro de chumbo, reação com solução de acetato de cobre e reação com acetato de chumbo e ácido acético glacial); 2 - saponinas (métodos: reação de Rossol, reação de Mitchell, reação de Rosenthalen, reação com reativo sulfo-vanílico e reação de Liebermann); 3 - flavonóides (métodos: reação de Shinoda, reação com cloreto de alumínio, reação com cloreto férrico e reação com hidróxido de sódio); e 4 - alcalóides (métodos: reagente de Sheibler, reagente de Bourchardat, reagente de Bertrand, reagente de Mayer e reagente de Dragendorff).

\section{Resultados e Discussão}

Os resultados obtidos nos bioensaios com extratos aquosos de folhas frescas, secas e frutos de pingode-ouro demonstraram alterações na germinação de alface e tomate. A porcentagem de germinação (PG) de aquênios de alface não foi alterada pelas concentrações dos extratos, comparados ao controle (Figura 1A). No entanto, ocorreram reduções na PG de sementes de tomate à medida que aumentava a concentração dos extratos aquosos de folhas frescas e secas; extratos de frutos ocasionaram reduções na PG de sementes de tomate apenas na concentração 4\% comparados ao controle (Figura 1B). Dados semelhantes de PG foram obtidos por Gatti et al. (2004), utilizando extratos aquosos de Aristolochia esperanzae sobre a germinação de sementes de alface e rabanete. Dados semelhantes também foram obtidos por Medeiros e Lucchesi (1993), ao testar efeito alelopático de ervilhaca (Vicia sativa) sobre alface e para Gorla e Perez (1997), ao testar ação de extratos de Miconia albicans e Lantana camara sobre a germinação de sementes de tomate.

Para o parâmetro velocidade de germinação (VG), o aumento da concentração de todos os extratos aquosos de folhas frescas de pingo-de-ouro provocou atrasos na VG de aquênios de alface. Extratos de folhas secas ocasionaram atrasos na VG de alface na concentração $4 \%$ e extratos de frutos nas concentrações 1 e $4 \%$, comparados ao controle (Figura 1C). Quanto às sementes de tomate, observa-se que atrasos na VG foram ocasionadas por extratos aquosos de folhas frescas e secas de pingo-de-ouro nas concentrações 2 e 4\%. Extratos de frutos não influenciaram na VG de sementes de tomate (Figura 1D). Periotto et al. (2004) evidenciaram que o aumento da concentração dos extratos aquosos de Andira humilis provocou reduções na velocidade de germinação de sementes de alface e rabanete. Dados semelhantes também são evidenciados por Medeiros e Lucchesi (1993), Gorla e Perez (1997) e Gatti et al. (2004), em testes alelopáticos.

Extratos aquosos (1, 2 e 4\%) de folhas frescas e secas de pingo-de-ouro reduziram, significativamente, de forma proporcional ao aumento da concentração, o índice de velocidade de germinação (IVG) de aquênios de alface. Extratos de frutos não alteraram o IVG dos aquênios de alface comparados ao controle (Figura 1E). Para as sementes de tomate, os resultados são semelhantes aos obtidos para alface. Extratos de folhas frescas e secas diminuíram o IVG em todas as concentrações utilizadas e extratos de frutos não alteraram o IVG das sementes de tomate comparados ao controle (Figura 1F). Para Wandscheer e Pastorini (2008), extratos de raízes e folhas de Raphanus raphanistrum provocaram alterações no índice de velocidade de germinação de sementes de alface. Variações muito grandes nos parâmetros testados indicam, segundo Labouriau e Agudo (1987), perda de sincronia nas reações metabólicas da germinação, demonstrando heterogeneidade na fisiologia dos aquênios tratados.

$\mathrm{O}$ crescimento inicial das plântulas de alface e tomate foi afetado significativamente com o aumento da 


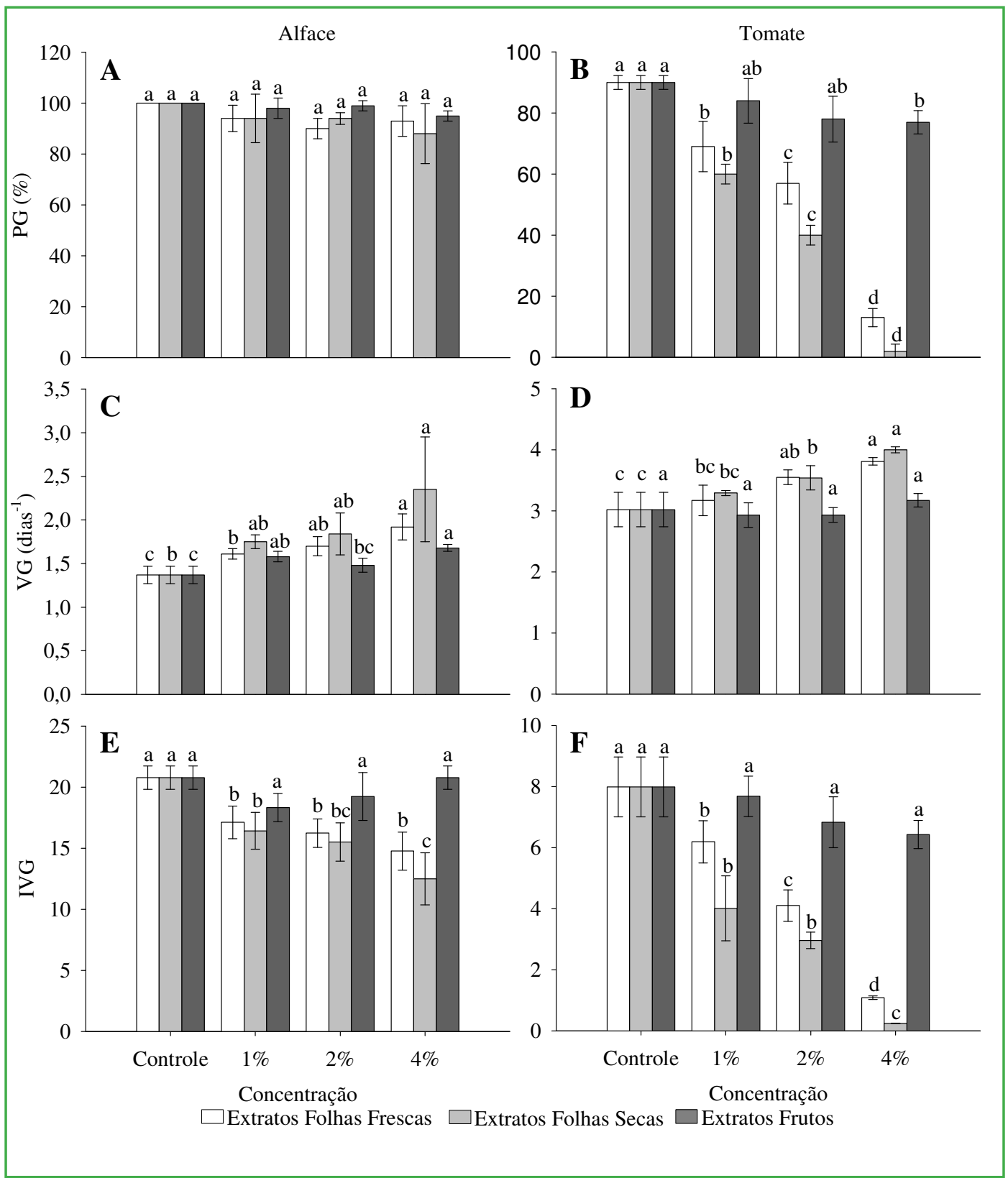

FIGURA 1: Média \pm desvio padrão da porcentagem de germinação (PG), velocidade de germinação (VG) e índice de velocidade de germinação (IVG) de aquênios de alface e tomate submetidos a diferentes concentrações dos extratos aquosos de folhas frescas, folhas secas e frutos de pingo-de-ouro. Letras minúsculas comparando as concentrações (controle, 1, 2 e 4\%) para cada tipo de extrato, separadamente. Letras iguais não diferem pelo teste de Tukey a $5 \%$ de probabilidade.

concentração dos extratos. Extratos aquosos de folhas frescas e secas $(1,2$ e $4 \%)$ de pingo-de-ouro reduziram significativamente o comprimento radicular das plântulas de alface, enquanto que extratos de frutos na concentração $2 \%$ estimularam o crescimento, das plântulas sendo o comprimento radicular da alface superior ao controle (Figura 2A). Com relação ao comprimento radicular do tomate todas as concentrações de extratos testadas
$(1,2$ e $4 \%)$ de folhas frescas, secas e frutos provocaram reduções significativas no comprimento radicular das plântulas (Figura 2B).

O comprimento da parte aérea de plântulas de alface não diferiu do controle quando utilizados extratos aquosos de frutos, no entanto, extratos de folhas frescas e secas de pingo-de-ouro reduziram o comprimento 
da parte aérea de plântulas de alface (na concentração de $1 \%$ com extrato de folhas frescas e 2 e $4 \%$ com o extrato de folhas secas) (Figura 2C). Para plântulas de tomate, os extratos de folhas secas e frutos também não diferiram do controle, sendo que apenas os extratos de folhas frescas alteraram a parte aérea nas concentrações de 2 e $4 \%$ (figura 2D).

Tratamentos submetidos a extratos de folhas secas a 4\% não apresentaram material suficiente para análise de comprimento (Figuras 2B e D).

O aparecimento de plântulas anormais, com raízes primárias atrofiadas e defeituosas, com ausência de raiz secundária e necrose radicular foi também observado (dados não apresentados). Todavia, esta alteração restringiu-se às plântulas submetidas aos extratos mais concentrados. Sintomas semelhantes aos obtidos nos testes com alface foram observados por Gatti et al.
(2004), Periotto et al. (2004), Maraschin-Silva e Aquila (2006a; 2006b).

Em plântulas de milho, o comprimento da radícula e da parte aérea foi significativamente afetado quando as plântulas eram submetidas a extratos de frutos de Ilex paraguariensis (Miró et al., 1998). Dados semelhantes ao comprimento de plântulas de alface também foram obtidos por Peres et al. (2004) ao testar ação alelopática de espécies de Pteridaceae (Adiantopsis radiata, Adiantum serratdentatum, Adiantum tetraphyllum e Pityrogramma calomelanos) e por Maraschin-Silva e Aquila (2006b) em testes alelopáticos de plantas nativas brasileiras (Cecropia pachystachya, Peltophorum dubium, Psychotria leiocarpa, Sapium glandulatum e Sorocea bonplandii).

O crescimento inicial das plântulas é mais sensível que a germinação, pois para cada semente o fenômeno é

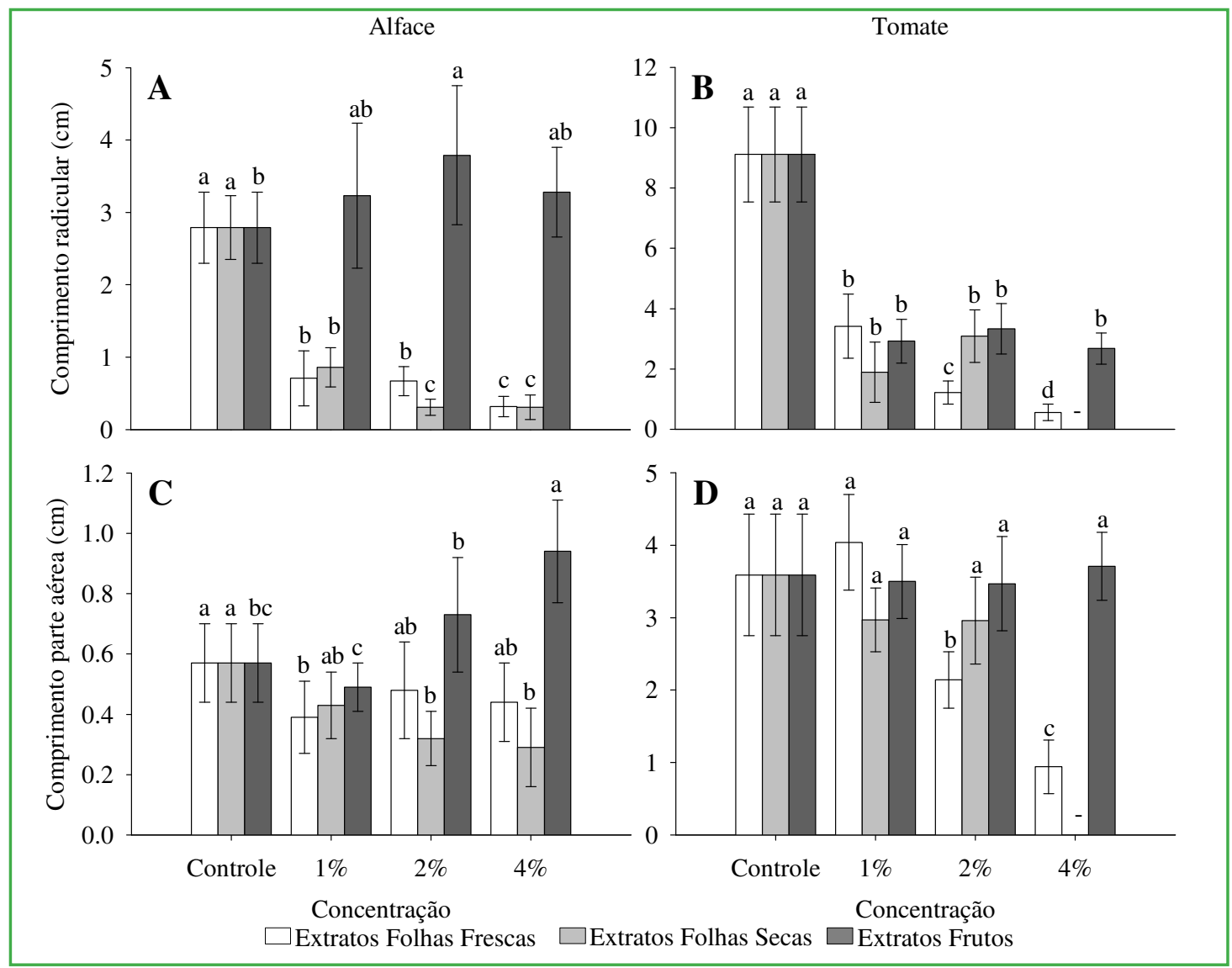

FIGURA 2: Média \pm desvio padrão do comprimento radicular e da parte aérea de plântulas de alface e tomate submetidas a diferentes concentrações dos extratos aquosos de folhas frescas, folhas secas e frutos de pingo-de-ouro. Letras minúsculas comparando as concentrações (controle, 1, 2 e 4\%) para cada tipo de extrato, separadamente. Letras iguais não diferem pelo teste de Tukey a $5 \%$ de probabilidade. (-) análise não realizada. 
discreto, germinando ou não (Ferreira e Aquila, 2000). Em geral, as raízes são mais sensíveis às substâncias presentes nos extratos quando comparadas com as demais estruturas das plântulas (Chon et al., 2000). Isso se deve ao fato das raízes estarem em contato direto e prolongado com o extrato (aleloquímicos) em relação às demais estruturas das plântulas (Chung et al., 2001) e/ ou a um reflexo da fisiologia distinta entre as estruturas (Aquila et al., 1999).

Quanto à massa fresca (MF) das plântulas de alface, observou-se que as concentrações dos extratos de folhas frescas $(2$ e $4 \%)$ e folhas secas $(1,2$ e $4 \%)$ de pingode-ouro provocaram reduções significativas na massa fresca das plântulas de alface e extratos de frutos não influenciaram significativamente na massa fresca das plântulas de alface comparados ao controle (Figura 3A). Para plântulas de tomate, os extratos não interferiram na massa fresca, com exceção de extratos de folhas frescas a $1 \%$ que ocasionaram aumento na MF (Figura 3B).

Em análise da massa seca (MS), todos os extratos e em todas as concentrações de pingo-de-ouro reduziram a massa seca de plântulas de alface comparados ao controle, com exceção de extratos de frutos $1 \%$ (Figura 3C). Para a massa seca de plântulas de tomate não foram registradas alterações significativas entre as concentrações utilizadas (Figura 3D). Quanto ao conteúdo de água (CA), os extratos aquosos de folhas frescas e secas não alteraram o CA das plântulas de alface, enquanto que plântulas de alface submetidas aos extratos de frutos o CA foi maior em relação ao controle (Figura 3E). Para plântulas de tomate, os extratos em todas as concentrações não provocaram alterações no CA comparados ao controle (Figuras 3F).

Plântulas de tomate submetidas a extratos de folhas frescas e secas a $4 \%$ não apresentaram material suficiente para análise de MF, MS e CA (Figuras 3B, D e F).

Carmo et al. (2007) observaram que extratos de folhas e cascas de tronco de canela-sassafrás (Ocotea odorifera) provocaram aumento da massa fresca de raízes das plântulas de sorgo, sem afetar a massa fresca da parte aérea. No entanto, a massa seca tanto das raízes quanto da parte aérea foi afetada em todas as concentrações testadas. Para Medeiros e Lucchesi (1993), os extratos de ervilhaca ( $V$. sativa) não interferiram no peso da matéria seca de plântulas de alface. Por outro lado, os extratos de frutos de erva-mate reduziram o peso seco da raiz e da parte aérea de plântulas de milho em todas as concentrações testadas (Miró et al., 1998). Gatti et al. (2004) citaram que estas variações podem ser explicadas devido a um investimento diferenciado de matéria orgânica, ou na raiz ou na parte aérea, influenciada diretamente pelo tipo e concentração do extrato.

A análise do $\mathrm{pH}$ dos extratos aquosos de folhas frescas, secas e frutos do pingo-de-ouro mostrou baixa variação de valores e baixa acidez, estando os valores entre 6,21 a 6,25 (Tabela 1). Os valores de potencial osmótico dos extratos variaram entre $-0,007$ a $-0,092$ $\mathrm{MPa}$, estando dentro do limite recomendado para a germinação de sementes de alface e tomate (Gatti et al., 2004) (Tabela 1). Valores semelhantes de $\mathrm{pH}$ e potencial osmótico dos extratos foram encontrados por Periotto et al. (2004), Maraschin-Silva e Aquila (2006a; 2006b) e Wandscheer e Pastorini (2008).

TABELA 1: Características físico-químicas $(\mathrm{pH}$ e potencial osmótico) dos extratos aquosos de folha fresca, folha seca e fruto de pingode-ouro.

\begin{tabular}{lcc}
\hline \multicolumn{1}{c}{ Extrato } & pH & PO (-MPa) \\
\hline Controle & 6,9 & 0,000 \\
Folha fresca 1\% & 6,3 & 0,014 \\
Folha fresca 2\% & 6,22 & 0,021 \\
Folha fresca 4\% & 6,21 & 0,026 \\
Folha seca 1\% & 6,25 & 0,031 \\
Folha seca 2\% & 6,22 & 0,051 \\
Folha seca 4\% & 6,21 & 0,092 \\
Fruto 1\% & 6,25 & 0,009 \\
Fruto 2\% & 6,22 & 0,070 \\
Fruto 4\% & 6,26 & 0,021 \\
\hline
\end{tabular}

PO: Potencial osmótico.

A verificação do $\mathrm{pH}$ e do potencial osmótico é importante, pois os extratos podem conter solutos como açúcares, aminoácidos e ácidos orgânicos que podem mascarar o efeito alelopático dos extratos por interferir no $\mathrm{pH}$ e serem osmoticamente ativos (Ferreira e Aquila, 2000). Esses solutos podem alterar a propriedade da água, resultando numa pressão osmótica diferente de zero na solução (Villela et al., 1991). 


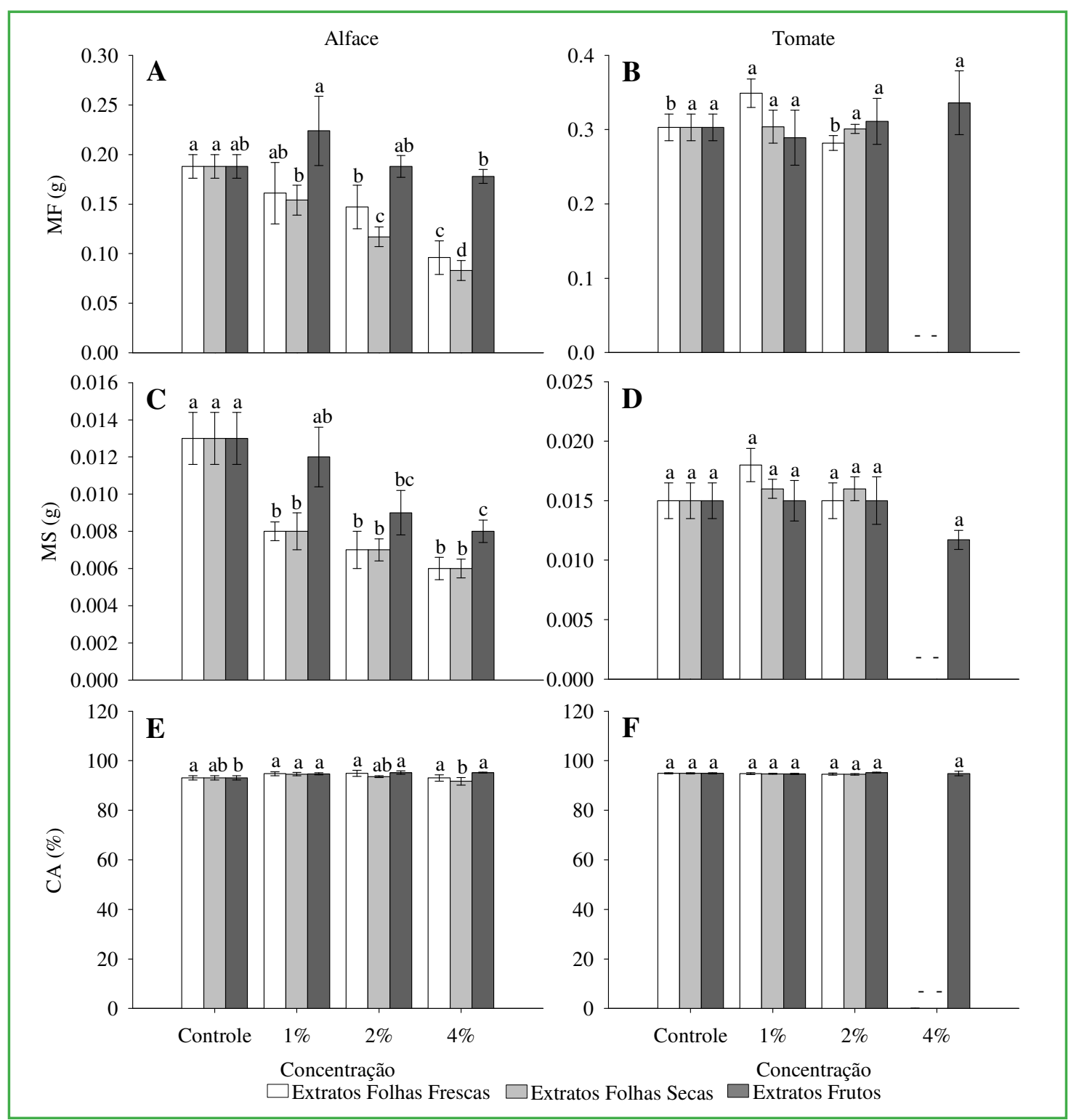

FIGURA 3: Média \pm desvio padrão da massa fresca (MF), massa seca (MS) e conteúdo de água (CA) de plântulas de alface submetidas a diferentes concentrações dos extratos aquosos de folhas frescas, folhas secas e frutos de pingo-de-ouro. Letras minúsculas comparando as concentrações (controle, 1, 2 e 4\%) para cada tipo de extrato, separadamente. Letras iguais não diferem pelo teste de Tukey a 5\% de probabilidade. (-) análise não realizada.

Dados na literatura indicam que tanto a germinação como o crescimento das plântulas é afetado quando o pH é extremamente alcalino ou extremamente ácido (Roy, 1986), com efeitos deletérios observados em condições de $\mathrm{pH}$ abaixo de 4 e superior a 10 (Eberlein, 1987). Gatti et al. (2004) consideram adequado para germinação de sementes que os valores de potencial osmótico não ultrapassem -0,2 MPa em testes alelopáticos.

A análise fitoquímica, pela detecção de compostos de metabolismo secundário, nos extratos das folhas frescas, secas e frutos do pingo-de-ouro foi positiva para alguns compostos (Tabela 2). Os flavonóides representam uma importante classe de polifenóis com forte atividade biológica e sua presença em vegetais parece estar associada com funções de defesa, controle de hormônios vegetais, inibição de enzimas e agentes alelopáticos. Saponinas, entre outros efeitos, apresentam ação sobre a membrana das células, modificando a permeabilidade celular (Alves e Santos, 2002). 
TABELA 2: Identificação de aleloquímicos em folhas frescas, secas e frutos de pingo-de-ouro.

\begin{tabular}{lcccc}
\hline \multicolumn{1}{c}{ Extrato } & Flavonóides & Alcalóides & Saponinas & Taninos \\
\hline Folhas frescas & - & - & + & - \\
Folhas secas & - & - & + & - \\
Frutos & + & - & + & - \\
\hline
\end{tabular}

(+) presença, (-) ausência.

Marashin-Silva e Aquila (2006b) relatam a presença de saponinas nas espécies Cecropia pachystachya, Peltophorum dubium, Psychotria leiocarpa, Sapium glandulatum e Sorocea bonplandii e de flavonóides nas espécies C. pachystachya e P. dubium. Os autores ainda consideram que caso os compostos tenham sido extraídos, os mesmos podem ser considerados como responsáveis, pelo menos em parte, nos resultados obtidos em testes alelopáticos envolvendo alface como planta alvo.

Contudo, não se pode afirmar que a presença desses compostos, mesmo estando presentes nos extratos da planta, tenha ocasionado os efeitos alelopáticos sobre a alface e tomate, visto que as reações foram apenas de determinação de presença ou ausência. Além disso, mesmo que estes metabólitos estejam presentes nos vegetais, nem sempre atuam como aleloquímicos. No entanto, com base nos resultados obtidos, sugerese que compostos alelopáticos (incluindo ou não os compostos detectados) estavam presentes nos extratos e ocasionaram tais efeitos. Cabe ressaltar que os resultados obtidos em laboratório para alelopatia podem não se confirmar em condições naturais, visto a ocorrência simultânea de fatores bióticos e abióticos que podem interferir nos resultados finais.

Diante dos métodos utilizados e dos resultados obtidos pode-se concluir que:

- extratos aquosos de folhas frescas, secas e frutos de pingo-de-ouro apresentam potencial alelopático sobre a alface e tomate, pois interferiram na germinação e no crescimento inicial dos mesmos, estando o $\mathrm{pH}$ e o potencial osmótico desvinculados de possíveis interferências.

- os efeitos ocasionados pelo pingo-de-ouro são crescentes à medida que se eleva a concentração dos extratos, com efeitos mais significativos ocasionados pelas concentrações de extratos de folhas frescas e secas a $4 \%$.

\section{Referências}

Alves, S. M.; Santos, L. S. 2002. Natureza química dos agentes alelopáticos. In: Souza Filho, A. P. S. \& Alves, S. M. (Eds). Alelopatia princípios básicos e aspectos gerais. Embrapa Amazônia Oriental, Belém, Brasil, p.25-48.

Aquila, M. E. A.; Ungaretti, J. A. C.; Michelin, A. 1999. Preliminary observation on allelopathic activity in Achyrocline satureoides (Lam.) DC. Acta Horticulturae, 502: 383-388.

Carmo, F. M. S.; Borges, E. E. L.; Takaki, M. 2007. Alelopatia de extratos aquosos de canela-sassafrás (Ocotea odorifera (Vell.) Rohwer). Acta Botanica Brasilica, 21 (3): 697-705.

Chon, S. U.; Coutts, J. H.; Nelson, C. J. 2000. Effects of light, growth media, and seedling orientation on bioassays of alfalfa autotoxicity. Agronomy Journal, 92: 715-720.

Chou, C. H. 1999. Roles of allelopathy in plant biodiversity and sustainable agriculture. Critical Reviews in Plant Sciences, 18 (5): 609-630.

Chou, C. H. 2006. Introduction to allelopathy. In: Reigosa, M. J.; Pedrol, N.; González, L. (Eds). Allelopathy: A physiological process with ecological implications. Springer, Dordrecht, Holanda, p.1-9.

Chung, I. M.; Ahn, J. K.; Yun, S. J. 2001. Assessment of allelopathic potential of barnyard grass (Echinochloa crus-gall) on rice (Oriza sativa L.) cultivars. Crop Protection, 20 (10): 921-928.

Costa, A. F. 2001. Farmacognosia. Fundação Calouste Gulbenkian, Lisboa, Portugal, 992pp.

Delachiave, M. E. A. P.; Ono, E. O.; Rodrigues, J. D. 1999. Efeitos alelopáticos de grama-seda (Cynodon dactylon (L.) Pers.) na germinação de sementes de pepino, milho, feijão e tomate. Revista Brasileira de Sementes, 21 (1): 194-197.

Eberlein, C. V. 1987. Germination of Sorghum almum seeds and longevity in soil. Weed Science, 35 (6): 796-801.

Falkenberg, M. B.; Santos, R. I.; Simões, C. M. O. 2002. Introdução à análise fitoquímica. In: Simões, C. M. O.; Schenkel, E. P.; Gosmsnn, G.; Mello, J. C. P.; Mentz, L. A.; Petrovick, P. R. Farmacognosia: Da planta ao medicamento. Universidade/UFRGS/UFSC, Porto alegre/Florianópolis, Brasil, p.165-182.

Ferreira, A. G.; Aquila, M. E. A. 2000. Alelopatia: Uma área emergente da ecofisiologia. Revista Brasileira de Fisiologia Vegetal, 12 (edição especial): 175-204.

Ferreira, A. G.; Aquila, M. E. A.; Jacobi, U. S.; Rizvi, V. 1992. Allelopathy in Brazil. In: Rizvi, S. J. H.; Rizvi, V. (Eds). Allelopathy: Basic and applied aspects. Chapman \& Hall, London, UK, p.243250.

Gatti, A. B.; Perez, S. C. J. G. A.; Lima, M. I. S. 2004. Efeito alelopático de Aristolochia esperanzae O. Kuntze na germinação e no crescimento de Lactuca sativa L. e Raphanus sativus L. Acta Botanica Brasilica, 18 (3): 459-472.

Gorla, C. M.; Perez, S. C. J. G. A. 1997. Influência de extratos aquosos de Miconia albicans Triana, Lantana camara L., Leucaena leucocephala (Lam) de Wit e Drimys winteri Forts, na germinação e crescimento inicial de sementes de tomate e pepino. Revista Brasileira de Sementes, 19 (2): 260-265.

Inderjit; Dakshini, K. M. M. 1995. On laboratory bioassays in allelopathy. The Botanical Review, 61 (1): 28-44. 
King, S. R.; Ambika, R. 2002. Allelopathic plants. 5. Chromolaen odorata (L.). Allelopathy Journal, 9 (1): 35-41.

Labouriau, L. F. G.; Agudo, M. 1987. On the physiology of seed germination in Salvia hispanica L. I. Temperatura effects. Anais da Acadêmia Brasileira de Ciências, 59 (1): 37-56.

Lorenzi, H.; Souza, H. M. 2001. Plantas ornamentais no Brasil: Arbustivas, herbáceas e trepadeiras. $3^{\mathrm{a}}$ ed. Plantarum, Nova Odessa, Brasil, 1088pp.

Macías, F. A.; Molinillo, J. M. G; Varela, R. M.; Galindo, J. C. G. 2007. Allelopathy - A natural alternative for weed control. Pest Management Science, 63: 327-348.

Macías, F. A.; Varela, R. M.; Torres, A.; Oliva, R. M.; Molinillo, J. M. G. 1998. Bioactive norsesquiterpenes from Helianthus annuus with potential allelopathic activity. Phytochemistry, 48 (4): 631636.

Maraschin-Silva, F.; Aquila, M. E. A. 2006a. Contribuição ao estudo do potencial alelopático de espécies nativas. Revista Árvore, 30 (4): 547-555.

Maraschin-Silva, F.; Aquila, M. E. A. 2006b. Potencial alelopático de espécies nativas na germinação e crescimento inicial de Lactuca sativa L. (Asteraceae). Acta Botanica Brasilica, 20 (1): 61-69.

Marenco, R. A.; Lopes, N. F. 2005. Fisiologia vegetal: Fotossíntese, respiração, relações hídricas e nutrição mineral. UFV, Viçosa, Brasil, 451pp.

Medeiros, A. R. M.; Lucchesi, A. A. 1993. Efeitos alelopáticos da ervilhaca (Vicia sativa L.) sobre a alface em testes de laboratório. Pesquisa Agropecuária Brasileira, 28 (1): 9-14.

Miró, C. P.; Ferreira, A. G.; Aquila, M. E. A. 1998. Alelopatia de frutos de erva-mate (Ilex paraguariensis) no desenvolvimento do milho. Pesquisa Agropecuária Brasileira, 33 (8): 261-270.

Pedrol, N.; González, L.; Reigosa, M. J. 2006. Allelopathy and abiotic stress. In: Reigosa, M. J.; Pedrol, N.; González, L. (Eds). Allelopathy: A physiological process with ecological implications. Springer, Dordrecht, Holanda, p.171-209.
Peres, M. T. L. P.; Silva, L. B.; Faccenda, O.; Hess, S. C. 2004. Potencial alelopático de espécies de Pteridaceae (Pteridophyta). Acta Botanica Brasilica, 18 (4): 723-730.

Periotto, F.; Perez, S. C. J. G. A.; Lima, M. I. S. 2004. Efeito alelopático de Andira humilis Mart. Ex Benth na germinação e no crescimento de Lactuca sativa L. e Raphanus sativus L. Acta Botanica Brasilica, 18 (3): 425-430.

Olofsdotter, M.; Mallik, A. U. 2001. Allelopathy symposium. Agronomy Journal, 93 (1): 1-2.

Rice, E. L. 1984. Allelopathy. $2^{\text {th }}$ ed. Academic Press, New York, USA, 422pp.

Rizvi, S. J. H.; Haque, H.; Singh, V. K.; Rizvi, V. 1992. A discipline called allelopathy. In: Rizvi, S. J. H.; Rizvi, V. (Eds). Allelopathy: Basic and applied aspects. Chapman \& Hall, London, UK, p.110.

Rodrigues, B. N; Passini, T.; Ferreira, A. G. 1999. Research on allelopathy in Brazil. In: Narwal, S. S (Ed.). Allelopathy update. Science Publishers, New Hampshire, USA, p.307-323.

Roy, M. M. 1986. Effects of pH on germination of Dichrostachys cineria (L.). Wegth \& Arn. Journal Tree Science, 5 (1): 62-64.

Salisbury, F. B.; Ross, C. 1992. Plant physiology. Wadsworth, Belmont, USA, 682pp.

Smith, A. E.; Martin, D. L. 1994. Allelopathic characteristics of three cool-season grass in the forage ecosystems. Agronomy Journal, 8 (2): 243-246.

Vieira, R. D.; Carvalho, N. M. 1994. Testes de vigor em sementes. Funep, Jaboticabal, Brasil, 164pp.

Villela, F. A.; Doni Filho, L.; Sequeira, E. L. 1991. Tabela de potencial osmótico em função da concentração de polietileno glicol 6.000 e da temperatura. Pesquisa Agropecuária Brasileira, 26 (11/12): 1957-1968.

Wandscheer, A. C. D.; Pastorini, L. H. 2008. Interferência alelopática de Raphanus raphanistrum L. sobre a germinação de Lactuca sativa L. e Solanum licopersycon L. Ciência Rural, 38 (4): 949-953. 